\title{
Graded replacement of corn grain with molassed sugar beet pulp modulates the fecal microbial community and hindgut fermentation profile in lactating dairy cows
}

Renee Maxine Petri, ${ }^{*} \dagger$ Matthias Münnich, ${ }^{*}$ Qendrim Zebeli, and Fenja Klevenhusen†¥ Institute of Animal Nutrition and Functional Plant Compounds, Department for Farm Animals and Veterinary Public Health, University of Veterinary Medicine Vienna, 1210 Vienna, Austria

\section{ABSTRACT}

High starch lactation diets not only enhance the risk of subacute ruminal acidosis but also of hindgut acidosis, which increases the risk of dysbiosis and the depression of fiber degradation. We recently showed that replacing corn with molassed sugar beet pulp $(\mathrm{Bp})$ improved fiber degradation in high-producing dairy cattle, possibly because of an improvement of rumen and hindgut conditions for microbes by Bp feeding. However, little is known about the effects of high inclusion rates of $\mathrm{Bp}$ on hindgut microbes and fermentation. Thus fecal grab samples were taken from 18 high-yielding Simmental cows after $28 \mathrm{~d}$ of feeding 3 different levels of $\mathrm{Bp}$ (n $=6$ ) for bacterial $16 \mathrm{~S}$ rRNA amplicon sequencing. In addition, the reticular $\mathrm{pH}$ was continuously monitored with indwelling sensors and eating and ruminating behavior was evaluated with noseband sensors. The Bp inclusion rates were $0 \mathrm{~g} / \mathrm{kg}$ (i.e., no $\mathrm{Bp}$ inclusion as control, CON), $120 \mathrm{~g} / \mathrm{kg}$ (12Bp), or $240 \mathrm{~g} / \mathrm{kg}$ (24Bp) replacing corn grain and limestone on a dry matter basis. The amount of time spent eating and ruminating was unaffected by Bp level, and the daily fluctuation in the reticular $\mathrm{pH}$ was reduced by $25 \%$ with $\mathrm{Bp}$ inclusion from 0.8 in the CON diet to 0.6 in $24 \mathrm{Bp}$ fed animals. Also, the fecal $\mathrm{pH}$ tended to increase with dietary $\mathrm{Bp}$ inclusion. Fecal acetate production showed a quadratic tendency with the lowest concentration $(58.9 \%)$ of the total short-chain fatty acid in the $12 \mathrm{Bp}$ treatment. Inclusion of $\mathrm{Bp}$ up to $24 \%$ of the diet decreased the fecal butyrate proportion by $27 \%$. The Shannon diver-

Received September 17, 2018.

Accepted February 5, 2019.

*These authors contributed equally to this work.

†Corresponding authors: fenja.klevenhusen@bfr.bund.de and renee. petri@vetmeduni.ac.at

$\ddagger$ Current address: The German Federal Institute for Risk Assessment (BfR), Unit Feed and Feed Additives, Department Safety in the Food Chain, 10589 Berlin, Germany. sity index was increased from 5.50 to 8.09 with dietary Bp inclusion indicating increased species diversity. Of the 200 most abundant operational taxonomic units, 25 were increased by dietary Bp inclusion, whereas 15 were decreased and 7 were quadratically affected. The second most abundant group was proposed taxon "CF231" of the family Paraprevotellaceae. Although it accounted for only $2.52 \%$ of the operational taxonomic units in the CON diet, it was increased by $64 \%$ with dietary $\mathrm{Bp}$ inclusion. The largest relative change in the abundance was found for the genus Fibrobacter that increased more than 14-fold from $0.04 \%(\mathrm{CON})$ to $0.66 \%(24 \mathrm{Bp})$. In conclusion, feeding molassed sugar beet pulp as partial substitution of corn up to $240 \mathrm{~g} /$ $\mathrm{kg}$ is a viable alternative that promotes ruminal and hindgut fermentation by supporting physiological $\mathrm{pH}$ and bacterial diversity.

Key words: sugar beet pulp, fiber, microbe, subacute ruminal acidosis

\section{INTRODUCTION}

Modern dairy diets have shifted from being forage based to grain and energy dense. These changes have supported the requirements of European dairy cows, which have more than doubled their milk production in the last $60 \mathrm{yr}$ (Oltenacu and Algers, 2005). Accordingly, the energy requirements of these animals have also greatly increased, resulting in a necessary shift from forage-based diets to the feeding of energy-dense diets. These diets contain large proportions of grains that are rich in starch. However, the use of these grainbased diets not only creates a competition for the use of human edible feedstuffs (Ertl et al., 2015; Münnich et al., 2017, 2018a) but feeding diets rich in starch has also been shown to decrease ruminal $\mathrm{pH}$ due to the rapid fermentation of dietary starch (Kleen et al., 2003). The intermittent depression of ruminal $\mathrm{pH}$ due to the accumulation of short-chain fatty acids (SCFA) and insufficient rumen buffering is referred to as SARA (Kleen et al., 2003; Plaizier et al., 2008; Zebeli and 
Metzler-Zebeli, 2012), with an increased risk of hindgut dysbiosis (Gressley et al., 2011) and systemic disorders such as inflammation and laminitis (Kleen et al., 2003).

To address these issues it is necessary to assess alternative energy sources other than starch-rich grains for feeding to ruminants. In this regard, fibrous byproducts of the food production chain are gaining increasing importance as alternative feedstuffs for dairy cows also in terms of a sustainable net food production (estimation of the human edible fraction in feedstuffs fed to livestock, in relation to the food produced by the animals; Ertl et al., 2015, 2016; Münnich et al., 2017). One such human inedible by-product of the sugar industry is molassed sugar beet pulp (Bp), which has long been used as an alternative energy source in cattle (Bhattacharya and Sleiman, 1971; Huhtanen, 1988). Münnich et al., (2018a) found that the replacement of corn grain with $24 \% \mathrm{Bp}$ is not only a viable alternative that improved net food production without impairing the cows' production performance and metabolic health status but also improved the digestibility of fiber. The reason for an improved digestibility of fiber was not understood, but an improvement of rumen and hindgut conditions for microbes to thrive by Bp feeding may be possible. In contrast to grains, Bp contains no starch and the carbohydrate fractions of $\mathrm{Bp}$ are mostly made of pectin and hemicelluloses, such as galactan and arabinan (Vojvodić et al., 2016). These carbohydrate components are less acidotic and considered conducive to rumen health (Alamouti et al., 2009), which may have a positive effect on microbial fermentation both in the rumen and the hindgut. Because of increased passage rate of digesta and a relative insufficiency of the rumen to digest diets low in physical structure (i.e., physically effective NDF fraction $>1.18 \mathrm{~mm}<32 \%$ of the ration; Humer et al., 2018) in high producing dairy herds, microbial ecology of the hindgut becomes more important (Gressley et al., 2011). However, there is limited research investigating the effects of feeding diets rich in $\mathrm{Bp}$ on hindgut fermentation and microbial ecology and relating this information to chewing behavior and rumen $\mathrm{pH}$. We hypothesized that replacing corn with Bp would decrease the content of starch and increase the amount of fiber in the diet, thus feeding diets with high proportions of $\mathrm{Bp}$ replacing corn grain might increase ruminal and fecal $\mathrm{pH}$. In addition, less starch would be available for degradation in the hindgut, increasing the hemicellulose fermenting bacteria populations and decreasing the risk of hindgut dysbiosis in high-producing dairy cattle. To improve our understanding of hindgut fermentation, the microbiome of fecal samples was analyzed using a next-generation sequencing approach and their metabolic profile by GC.

\section{MATERIALS AND METHODS}

\section{Animals and Experimental Design}

This report is part of a larger study with data on digestibility, production performance, and energy metabolism being published elsewhere (Münnich et al., 2018a). Details of the experiment are in that paper. In brief, the study was conducted as a longitudinal block randomized experimental design using 18 Simmental cows $(745 \pm 199 \mathrm{~kg}$ of BW; mean $\pm \mathrm{SD})$ in early lactation $(37.4 \pm 0.9 \mathrm{DIM})$. Prior to the experiment, cows were arranged into 3 groups with equal distribution for milk yield, DIM, and number of lactation (3.68 \pm 0.35 ). Diets tested were designed to meet or exceed the requirements of a dairy cow weighing $700 \mathrm{~kg}$ and producing $40 \mathrm{~kg}$ of milk per day. Three different levels of $\mathrm{Bp}$ in the diet were tested (Table 1). The control $\operatorname{diet}(\mathbf{C O N})$ contained no Bp. For the 12Bp diet, $12 \% \mathrm{Bp}$ was added to the diet at the expense of $11.7 \%$ ground corn grain and $0.3 \%$ limestone. In the $\mathbf{2 4 B p}$ diet, $24 \%$ Bp replaced $23.4 \%$ ground corn grain and all of the limestone. Limestone was decreased to keep equal contents of calcium among diets. All diets were fed as TMR that were prepared daily. Feed was provided at 0800 and feeding troughs were again refilled at $1800 \mathrm{~h}$ to allow ad libitum intake with a refusal of $10 \%$ of the fresh matter according to the feed intake of the previous day. Feeding troughs were equipped with computer-regulated access gates and electronic weighing scales (Insentec B.V., Marknesse, the Netherlands) that allowed individual feeding and the measurement of the daily feed intake of each cow. The experimental period lasted $28 \mathrm{~d}$, whereof the first $7 \mathrm{~d}$ of the experiment functioned as a baseline period, during which all cows were fed the CON diet. On the subsequent $21 \mathrm{~d}$ (i.e., d 8 to 28 of the experiment) cows were fed either the CON, $12 \mathrm{Bp}$, or $24 \mathrm{Bp}$ diet, according to their experimental group. Throughout the experiment cows had unrestricted access to fresh water and salt-lick stones. Twice daily, at 0700 and $1730 \mathrm{~h}$, cows were milked in a tandem milking parlor.

All procedures involving animal handling and treatment were approved by the institutional ethics committee of the University of Veterinary Medicine, Vienna, Austria, and the national authority according to $\S 26$ of the Law for Animal Experiments, Tierversuchsgesetz 2012, BGBl. I Nr. 114/2012 (GZ BMWFW68.205/0006-WF/V/3b/2016).

\section{Sampling}

Feed samples for proximate nutrient analysis were taken weekly, directly after the feed preparation. Milk 
Table 1. Ingredients and nutrient composition of the experimental diets

\begin{tabular}{|c|c|c|c|}
\hline \multirow[b]{2}{*}{ Item } & \multicolumn{3}{|c|}{ Treatment $^{1}$} \\
\hline & $\mathrm{CON}$ & $12 \mathrm{Bp}$ & $24 \mathrm{Bp}$ \\
\hline \multicolumn{4}{|l|}{ Diet ingredient $(\mathrm{g} / \mathrm{kg}$ of $\mathrm{DM})$} \\
\hline Grass silage & 450 & 450 & 450 \\
\hline Hay & 50 & 50 & 50 \\
\hline Corn grain & 334 & 217 & 100 \\
\hline Sugar beet pulp & 0 & 120 & 240 \\
\hline Rapeseed meal & 150 & 150 & 150 \\
\hline Limestone & 6 & 3 & 0 \\
\hline Mineral-vitamin $\operatorname{mix}^{2}$ & 10 & 10 & 10 \\
\hline \multicolumn{4}{|c|}{ Nutrient composition ( $\mathrm{g} / \mathrm{kg}$ of DM, unless stated) } \\
\hline $\mathrm{DM}$ ( $\mathrm{g} / \mathrm{kg}$ of fresh matter) & 483 & 482 & 488 \\
\hline $\mathrm{OM}$ & 916 & 915 & 906 \\
\hline $\mathrm{CP}$ & 158 & 161 & 160 \\
\hline $\mathrm{NDF}$ & 389 & 421 & 439 \\
\hline $\mathrm{ADF}$ & 234 & 249 & 268 \\
\hline $\mathrm{NFC}$ & 344.7 & 313 & 288 \\
\hline Starch & 225 & 143 & 78 \\
\hline Neutral detergent soluble fiber & 50 & 94 & 115 \\
\hline Ether extract & 23.0 & 20.4 & 17.9 \\
\hline
\end{tabular}

${ }^{1}$ Beet pulp inclusion rate: control diet $(\mathrm{CON})=0 \mathrm{~g} / \mathrm{kg}, 12 \mathrm{Bp}=120 \mathrm{~g} / \mathrm{kg}, 24 \mathrm{Bp}=240 \mathrm{~g} / \mathrm{kg}$.

${ }^{2}$ The mineral-vitamin mix contained (per gram of DM): $60.0 \mathrm{mg}$ of Ca, $40.0 \mathrm{mg}$ of P, $15 \mathrm{mg}$ of Na, $60.0 \mathrm{mg}$ of $\mathrm{Mg}, 1,000 \mathrm{IU}$ of vitamin A, $150 \mathrm{IU}$ of vitamin $\mathrm{D}_{3}, 4.0 \mathrm{mg}$ of vitamin E, $24.0 \mathrm{mg}$ of niacin, $0.29 \mathrm{mg}$ of I, 0.04 $\mathrm{mg}$ of $\mathrm{Co}, 1.6 \mathrm{mg}$ of $\mathrm{Cu}, 4.2 \mathrm{mg}$ of $\mathrm{Mn}, 6.8 \mathrm{mg}$ of $\mathrm{Zn}$, and $0.05 \mathrm{mg}$ of Se.

yield and DMI were measured during the baseline period (i.e., the first $7 \mathrm{~d}$ of the experiment) and on the last $7 \mathrm{~d}$ of the experiment. Reticular $\mathrm{pH}$ was measured continuously in 18 cows throughout the experiment using wireless $\mathrm{pH}$ sensors (smaXtec Premium, smaXtec Animal Care GmbH, Graz, Austria) that were orally placed into the reticulum before the experiment. For statistical analysis only data from d 22 to 28 were used to ensure proper adaptation to the diet. Eating and ruminating behavior was measured from d 25 to 28 using noseband sensors (Rumiwatch system, ITIN $+\mathrm{HOCH}$ GmbH, Fütterungstechnik, Liestal, Switzerland). On d 28, fecal grab samples were taken in the morning. Subsamples were frozen at $-80^{\circ} \mathrm{C}$ until determination of fecal $\mathrm{pH}$, SCFA pattern, and microbiome analysis.

\section{Laboratory Analysis}

Feed samples were analyzed for DM, OM, CP, NDF, ADF, and ether extract according to VDLUFA (2012) guidelines. Furthermore, feed samples were analyzed for their starch content, using a commercial starch assay kit (Megazyme Int., Wicklow, Ireland). Dietary neutral detergent soluble fiber (NDSF) content was analyzed as described by Hall et al. (1999). Fecal SCFA pattern was determined by GC. For sample preparation $1 \mathrm{~g}$ of fecal sample was diluted in $1 \mathrm{~mL}$ of water. Subsequently, $300 \mu \mathrm{L}$ of an internal standard (4-methylvaleric acid, Sigma-Aldrich, St. Louis, MO) and 200 $\mu \mathrm{L}$ of $25 \%$ phosphoric acid were added. Afterward, the samples were mixed thoroughly and centrifuged at $20,000 \times g$ for $20 \mathrm{~min}$ at room temperature and the supernatant was transferred into a fresh tube. Subsequently, supernatant was centrifuged several times until clear. Afterward GC was performed as described by Qumar et al. (2016).

\section{DNA Extraction and Sequencing}

For DNA extraction, $250 \mathrm{mg}$ of fecal sample was mixed with $1 \mathrm{~mL}$ of Inhibitex buffer, $4 \mathrm{~g}$ of autoclaved ceramic beads (Ø $1.4 \mathrm{~mm}$, QIAamp Fast DNA Stool Mini Kit, Qiagen, Carlsbad, CA), $100 \mu \mathrm{L}$ of $100 \mathrm{mg} /$ $\mathrm{mL}$ lysozyme, and $10 \mu \mathrm{L}$ of $2.5 \mathrm{U} / \mu \mathrm{L}$ mutanolysin (Sigma-Aldrich, Vienna, Austria). The sample was then incubated at $37^{\circ} \mathrm{C}$ (Friocell, MMM group, Munich, Germany). After 30 min of incubation, $20 \mu \mathrm{L}$ of $18.6 \mathrm{mg} / \mathrm{mL}$ proteinase K (Sigma-Aldrich) was added and incubation continued for $1 \mathrm{~h}\left(37^{\circ} \mathrm{C}\right)$. Subsequently, samples were homogenized by bead-beating $(3 \times 45$ min, speed: 4.5) after which the samples were centrifuged at $20,000 \times g$ for $1 \mathrm{~min}$ at room temperature. After centrifugation, the supernatant was transferred to a fresh tube.

Isolation of DNA was done with the QIAamp Fast DNA Stool Mini Kit (Qiagen) according to the manufacturer's instructions for fecal samples. First, 200 $\mu \mathrm{L}$ of supernatant was mixed with lysis buffer, and samples were vortexed for $15 \mathrm{~s}$ on the vortex adapter vortex genie 2 (Scientific Industries Inc., Bohemia, 
NY). Then $200 \mu \mathrm{L}$ of ethanol (96\%) was added, after which samples were briefly vortexed again. For DNA elution the samples were placed on spin columns, washed with buffers, and eluted with the ATE buffer provided. After isolation, total DNA quantity was measured using the Qubit Fluorometer 2.0 (Qubit dsDNA HS Assay Kit, Thermo Fisher Scientific, Vienna, Austria) according to the manufacturer's instructions and samples were stored at $-20^{\circ} \mathrm{C}$ until further analysis. Amplicon sequencing was performed using Illumina MiSeq paired-ends sequencing technology (Microsynth AG, Balgach, Switzerland). For amplification of the hypervariable region V3-V5 of the bacterial $16 \mathrm{~S}$ rRNA genes $(2 \times 300 \mathrm{bp})$ was performed, using the primer set 357F (5'-CCTACGGGAGGCAGCAG-3') and 926R (5'-CCGTCAATTCMTTTRAGT-3'; Peterson et al., 2009). Multiplexed libraries were constructed by ligating sequencing adapters and indices onto purified PCR products using the Nextera XT Sample Preparation Kit (Illumina, Balgach, Switzerland). Primers were trimmed and corresponding overlapping paired-end reads were stitched by Microsynth (Microsynth AG).

\section{Sequence Processing}

To perform data quality control and analyses the QIIME pipeline was used (Caporaso et al., 2010). A total of 4,072,757 raw reads were quality filtered based on length and quality of the reads using a phred quality score of Q20 ( $q=19)$, which resulted in 3,973,060 reads with an average final length of $508 \pm 45$ bp. Screening for chimeric sequences was done using USEARCH 8.1 and the gold.fa database (Edgar, 2010). Sequences were then aligned and clustered to define operational taxonomic units (OTU), using PyNAST (Caporaso et al., 2010) and the SILVA128 (https://www.arb-silva.de, version 123) database as a reference template. Identity of OTU was determined with $97 \%$ similarity of sequences to the database and OTU were defined with a minimum of 10 sequences or more. This resulted in $1,110,174$ reads and 5,024 OTU for analysis of the fecal microbiota samples. Alpha- (Chao1, Shannon index, Simpson, observed OTU) and $\beta$-diversity (unweighted Unifrac) analysis of the samples was also performed using QIIME. Sequences have been submitted to the National Center for Biotechnology Information (NCBI) sequence read archive under the accession numbers SARMN09644425 to SAMN09644442.

\section{Statistical Analysis}

Statistical analysis was performed using the mixed procedure of SAS (version 9.4, SAS Institute Inc., Cary, $\mathrm{NC}$ ). Cows were considered as individual experimental units and measured values from the same cow at different time points were defined as repeated measurements. The treatment was considered as the fixed effect and the average of the baseline period was used as a covariate to account for inter-animal differences. Parity of the cows was defined as a random factor. Post hoc testing using Tukey's was performed to compare significant differences between treatment means. Linear and quadratic effects were analyzed using the CONTRAST statement of SAS. Significance was declared at $P \leq$ 0.05 and tendencies were defined as $0.05<P \leq 0.10$.

\section{RESULTS}

\section{Diet Composition, Rumination, and Ruminal pH}

Partially replacing corn grain with $\mathrm{Bp}$ at a rate of $24 \%$ DM increased the dietary NDF and ADF content by 13 and $15 \%$, respectively (Table 1 ). For the same dietary $\mathrm{Bp}$ inclusion, the dietary NFC content decreased by $17 \%$. Furthermore, the NFC composition was thoroughly altered. Although starch accounted for $65 \%$ of the NFC in the CON diet, it accounted for only $27 \%$ of the NFC in the $24 \mathrm{Bp}$ diet. Starch was largely replaced by NDSF that accounted for $14 \%$ of the NFC in the CON diet and $40 \%$ of the NFC in the $24 \mathrm{Bp}$ diet.

Despite the increased dietary fiber content, no effect was found on DMI $(P=0.73)$ that averaged $3.12 \%$ of the BW over all diets (Table 2). Also, the amount of time spent eating was unaffected $(P=0.19)$. Furthermore, the ruminating time and the chews per bolus, as a measure for ruminating intensity, were unaffected $(P$ $>0.05)$ and averaged $557 \mathrm{~min} / \mathrm{d}$ and 60.4 chews per bolus, respectively. Dietary effects on ruminal $\mathrm{pH}$ were nonsignificant (Table 3). However, it has to be noted that the inter-animal variation was large, as can be seen in the standard error of the mean for daily time spent below $\mathrm{pH}$ 6. Accordingly, in every group at least one cow showed $\mathrm{pH}$ values beneath the SARA threshold (Neubauer et al., 2018) for long periods of the day. The daily average reticular temperature was unaffected and averaged $38.9^{\circ} \mathrm{C}$ over all groups.

\section{Fecal Fermentation}

Analysis of fecal grab samples revealed that the gradual replacement of corn grain with Bp tended to affect the fecal acetate proportion quadratically $(P=0.07$, Table 4) with the lowest concentration $(58.9 \%)$ of the total SCFA being found with the 12Bp diet. While no effect was found for the fecal propionate molar proportion $(P=0.75)$, which averaged $17.6 \%$ of total SCFA, dietary inclusion of $\mathrm{Bp}$ decreased the fecal butyrate proportion from $10.0 \%$ of the total SCFA in the CON 
Table 2. Eating and ruminating behavior of cows fed different amounts of molassed sugar beet pulp

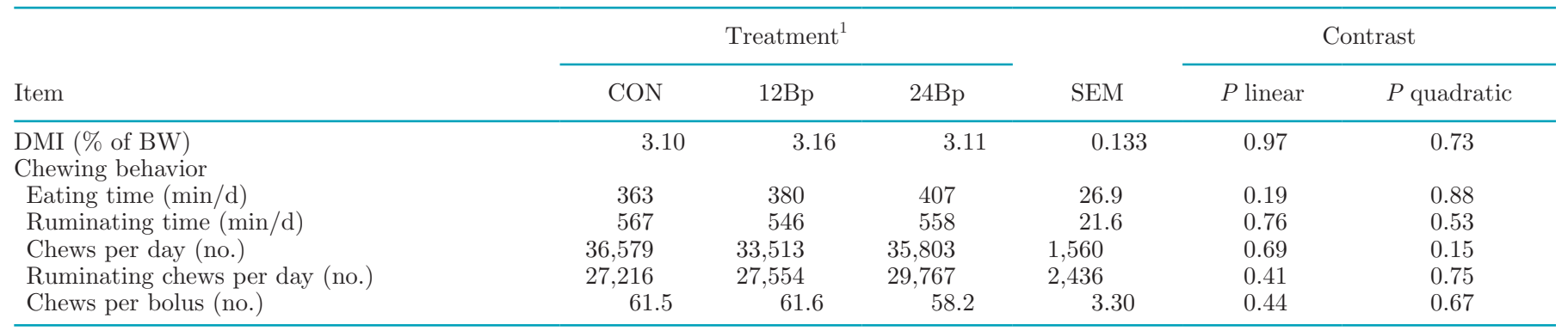

${ }^{1}$ Beet pulp inclusion rate: control diet $(\mathrm{CON})=0 \mathrm{~g} / \mathrm{kg}, 12 \mathrm{Bp}=120 \mathrm{~g} / \mathrm{kg}, 24 \mathrm{Bp}=240 \mathrm{~g} / \mathrm{kg}$.

diet to $7.3 \%$ in the $24 \mathrm{Bp} \operatorname{diet}(P<0.001)$. The fecal $\mathrm{pH}$ tended to increase with dietary Bp inclusion $(P=$ $0.09)$.

\section{Fecal Microbial Community}

Over all dietary treatments the number of observed OTU in the fecal samples was only numerically increased with Bp inclusion $(P=0.14)$ and averaged 2,442 OTU (Table 5). While the Chao1 Index only tended to increase by 335 points $(P=0.07)$, the Shannon index was increased $(P=0.04)$ from 7.50 to 8.09 with dietary Bp inclusion indicating increased species diversity. Using the unweighted Unifrac metric for principal coordinate analysis, a treatment grouping can be seen based on PC1 and PC3 (Figure 1).

The most abundant OTU was identified as Ruminococcaceae-like OTU1 at the $97 \%$ identity threshold. Of the 200 most abundant OTU, 34 were affected by the replacement of corn grain with $\mathrm{Bp}(P<0.05$; Figure 2). Of these 34 OTU 17 were increased by dietary Bp inclusion, whereas 9 were decreased, and 8 were quadratically affected. Using the SILVA128 database it was possible to assign up to 27 to $34 \%$ of all OTU to 37 known genera (Figure 3). The fecal microbiota was dominated by Firmicutes phylum $(\sim 51 \%)$, followed by Bacteriodetes $(\sim 42 \%)$ and Proteobacteria, which tended $(P=0.09)$ to decrease from 6 to $1.5 \%$ in relative abundance with increasing dietary Bp. Fibrobac- teres $(P=0.003)$ and Cyanobacteria $(P=0.001)$ were both linearly increased with the addition of $\mathrm{Bp}$ in the diet accounting for 0.7 and $0.3 \%$ of the total bacterial abundance in the $24 \mathrm{Bp}$ group, respectively. The most abundant genus $5-7 \mathrm{~N} 15$ belonging to the family Bacteroidaceae was found to linearly decrease (in tendency, $P=0.06$ ) with increasing dietary inclusion (Figure 3). Similarly, Succinivibrio, Phascolarctobacterium, Turicibacter, and Phenylobacterium all linearly decreased with enhanced Bp proportion in the diet. In contrast, CF231, Paludibacter, Fibrobacter, and Lachnospira increased linearly $(P=0.02, P=0.01, P=0.003$, and $P$ $=0.05$, respectively; Figure 3 ).

\section{DISCUSSION}

\section{Effects on Rumination and Reticuloruminal $\mathrm{pH}$}

The aim of the present study was to investigate the effects of substituting the starch source corn with the soluble fiber source $\mathrm{Bp}$ on hindgut microbes and fermentation. A single sampling of fecal content was performed at the end of a 28-d feeding period. As expected, replacing corn grain with $\mathrm{Bp}$ reduced the dietary starch content to a great extent and replaced it by dietary fiber in the form of NDF, ADF, and NDSF. Although increased dietary fiber levels are commonly expected to decrease the feed intake due to physical rumen fill (Voelker and Allen, 2003a), feed intake re-

Table 3. Reticular pH and temperature of cows fed different amounts of molassed sugar beet pulp

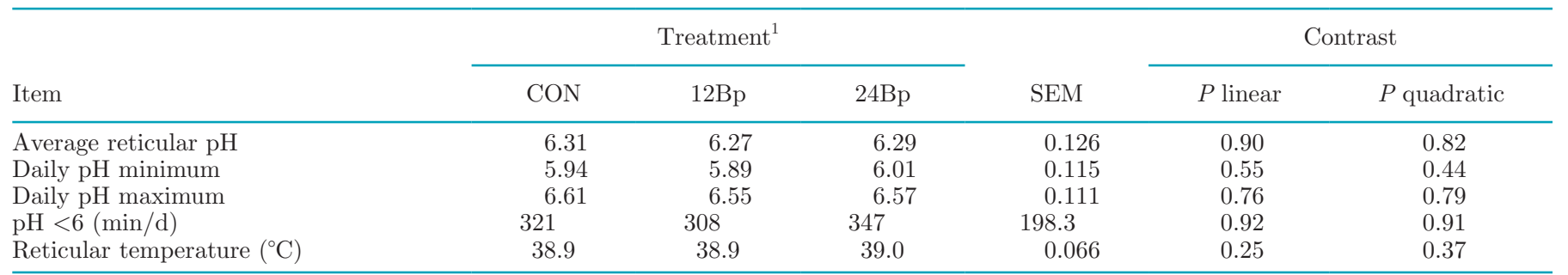

${ }^{1}$ Beet pulp inclusion rate: control diet $(\mathrm{CON})=0 \mathrm{~g} / \mathrm{kg}, 12 \mathrm{Bp}=120 \mathrm{~g} / \mathrm{kg}, 24 \mathrm{Bp}=240 \mathrm{~g} / \mathrm{kg}$. 
Table 4. Fecal short-chain fatty acid pattern and $\mathrm{pH}$ of cows fed different amounts of molassed sugar beet pulp

\begin{tabular}{|c|c|c|c|c|c|c|}
\hline Item & \multicolumn{3}{|c|}{ Treatment $^{1}$} & SEM & \multicolumn{2}{|c|}{ Contrast } \\
\hline Fecal pH & 7.42 & 7.50 & 7.67 & 0.0979 & 0.09 & 0.70 \\
\hline \multicolumn{7}{|l|}{ Molar proportion (\%) } \\
\hline Acetate (A) & 65.2 & 58.9 & 63.2 & 2.237 & 0.54 & 0.07 \\
\hline Propionate $(\mathrm{P})$ & 17.6 & 17.4 & 18.0 & 0.925 & 0.75 & 0.70 \\
\hline Isobutyrate & 2.22 & 2.40 & 2.52 & 0.202 & 0.30 & 0.91 \\
\hline Isovalerate & 1.86 & 1.94 & 2.04 & 0.162 & 0.45 & 0.97 \\
\hline $\mathrm{A}: \mathrm{P}$ & 3.73 & 3.44 & 3.52 & 0.150 & 0.32 & 0.36 \\
\hline
\end{tabular}

${ }^{\mathrm{a}-\mathrm{c}}$ Means with different superscripts differ significantly $(P<0.05)$.

${ }^{1}$ Beet pulp inclusion rate: control diet $(\mathrm{CON})=0 \mathrm{~g} / \mathrm{kg}, 12 \mathrm{Bp}=120 \mathrm{~g} / \mathrm{kg}, 24 \mathrm{Bp}=240 \mathrm{~g} / \mathrm{kg}$.

${ }^{2}$ Total short-chain fatty acids (calculated as total $\mu \mathrm{mol} / \mathrm{g}$ of DM feces).

mained unchanged by diet type (Münnich et al., 2018a), which has also been shown in other studies testing Bp (Dann et al., 2007; Fanchone et al., 2013). However, despite the increased dietary fiber content, no effect on rumination was found. The lack of a treatment effect in the present study suggests that the fiber content of molassed sugar beet pulp is not effective at stimulating chewing activity, possibly due to the small particle size and solubility. Fiber of adequate particle size $(>5 \mathrm{~mm})$ has been shown to promote chewing and rumination in dairy herds (Yang and Beauchemin, 2006). However, because the molassed sugar beet pulp used in this trial was first ground to $5 \mathrm{~mm}$, the fiber content of the beet pulp can be classified as non-physically effective fiber.

For assessing ruminal health, $\mathrm{pH}$ is considered a key indicator because it mirrors the balance between SCFA production from carbohydrate fermentation, SCFA neutralization by salivary and dietary buffers, and SCFA removal by absorption across the rumen wall and passage from the rumen (Allen, 1997; Aschenbach et al., 2011). A low ruminal pH is strongly associated with high-grain feeding (Zebeli et al., 2008a), possibly resulting in SARA, which is defined as intermittent drops below $\mathrm{pH} 5.8$ for more than $5.24 \mathrm{~h}$ per day (Zebeli et al., 2008b) or below pH 6.0 if measured in the reticulum with indwelling sensors (Neubauer et al., 2018). A previous in vitro study found that the replacement of corn grain with $\mathrm{Bp}$ does not reduce the fermentative activity in the rumen and the amount of SCFA produced (Münnich et al., 2018b). Thus a similar acidic potential can be assumed, which confirms the results found by Voelker and Allen (2003b), who found no difference in ruminal $\mathrm{pH}$ when diets with varying proportions of $\mathrm{Bp}$ and corn were fed. In the present study the forage source and proportion was the same in all groups; therefore, the diet's minimum physical effectiveness was equal and sufficient rumination and salivation to buffer the rumen was supported in all groups (Zebeli et al., 2007). Additionally, no differences in DMI and chewing activity were found; thus, the amount of salivation and buffering capacity of the digesta should be similar among feeding groups. This was supported by the lack of dietary effects on reticular $\mathrm{pH}$. However, in the present study the inter-animal variation was high, and per group at least one cow displayed ruminal $\mathrm{pH}$ values significantly exceeding the previously defined reticular $\mathrm{pH}$ threshold for SARA defined as 5 to $6 \mathrm{~h}$ per day below pH 6 (Neubauer et al., 2018). These results show that some cows had constant acidotic conditions in the rumen, even with low dietary starch provision, and be-

Table 5. Alpha-diversity of the microbiome of fecal grab samples of cows fed different amounts of molassed sugar beet pulp

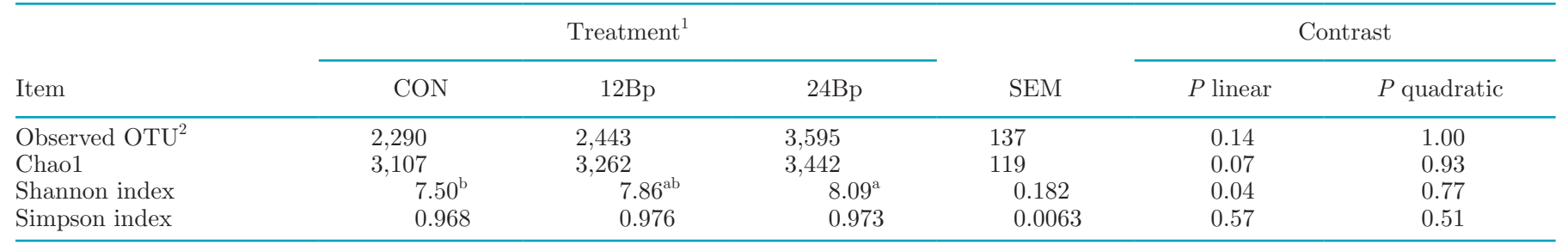

${ }_{\mathrm{a}, \mathrm{b}}$ Means with different superscripts differ significantly $(P<0.05)$.

${ }^{1}$ Beet pulp inclusion rate: control diet $(\mathrm{CON})=0 \mathrm{~g} / \mathrm{kg}, 12 \mathrm{Bp}=120 \mathrm{~g} / \mathrm{kg}, 24 \mathrm{Bp}=240 \mathrm{~g} / \mathrm{kg}$.

${ }^{2} \mathrm{OTU}=$ operational taxonomic units. 
cause none of the cows showed clinical signs of distress or symptoms associated with SARA, such as reduced feed intake, diarrhea, or laminitis (Plaizier et al., 2008), the currently defined $\mathrm{pH}$ thresholds for SARA might not be applicable for every cow. Accordingly, using $\mathrm{pH}$
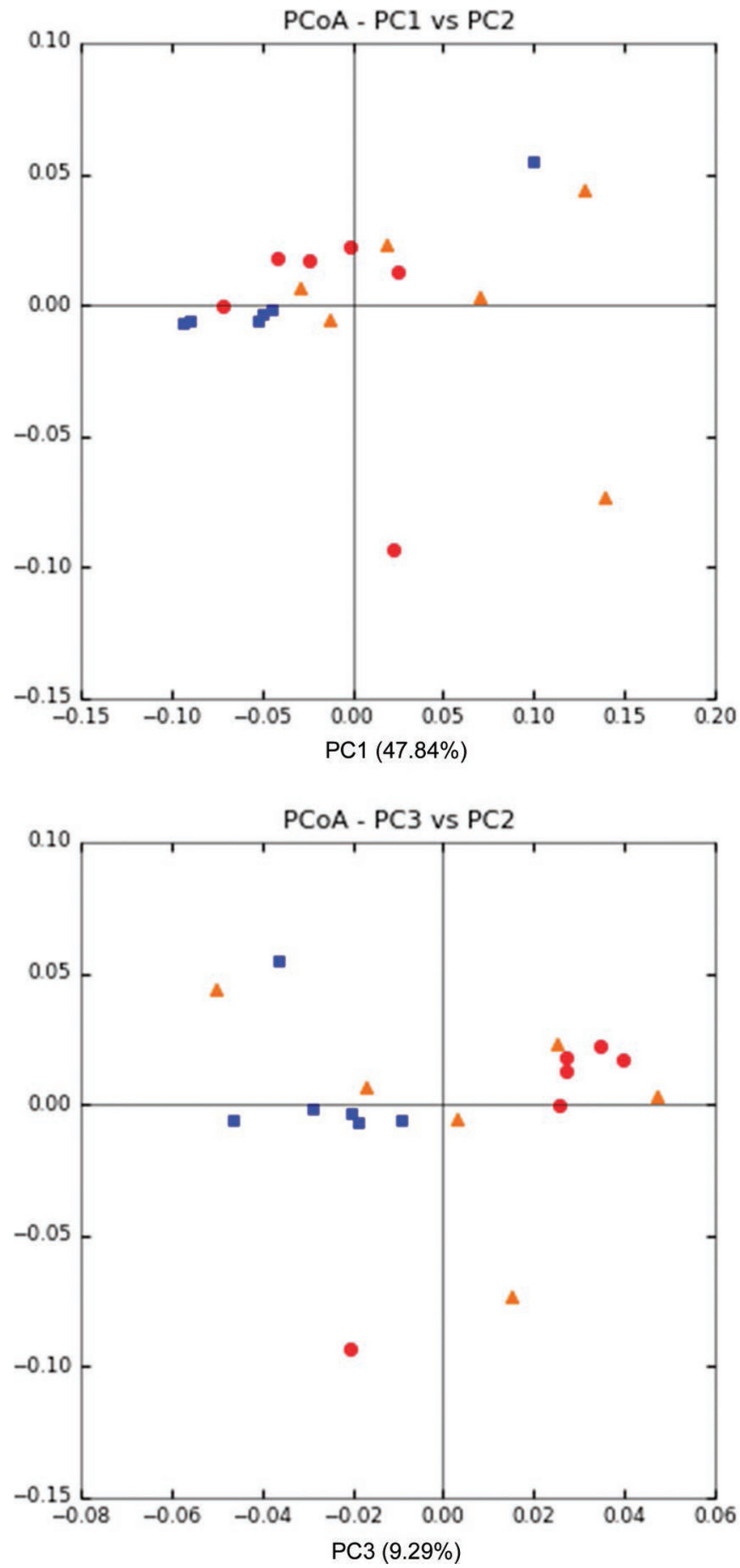

boluses to indicate SARA can only be recommended when a sufficient number of animals are surveyed, otherwise inter-animal variation could potentially mask herd health and the influence of feeding management (Humer et al., 2018).

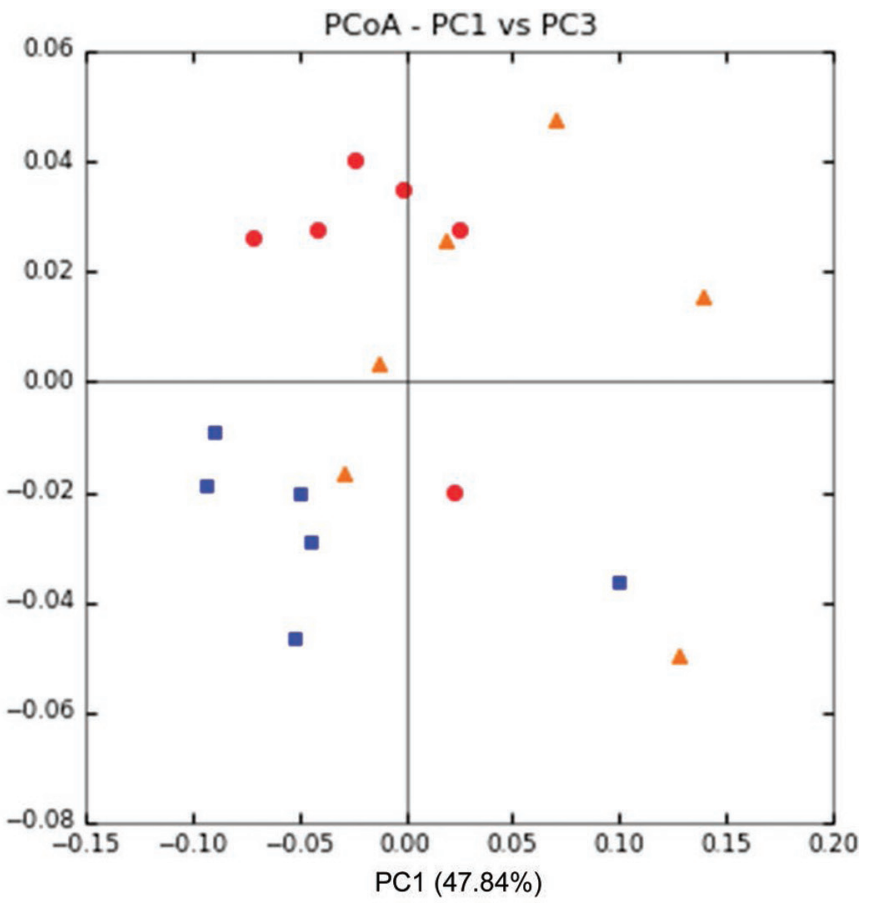

Figure 1. Beta-diversity of treatment groups based on unweighted Unifrac analysis in a 2-dimensional principal coordinate analysis (PCoA) plot. Principal components (PC; PC1: 47.8\%; PC2: 11.8\%; PC3: 9.3\%) explain 67\% of the total variation between samples. Orange triangles: control $(\mathrm{CON})$; red circles: $120 \mathrm{~g} / \mathrm{kg}$ beet pulp inclusion rate $(12 \mathrm{Bp})$; blue squares: $240 \mathrm{~g} / \mathrm{kg}$ beet pulp inclusion rate (24Bp). 


\begin{tabular}{|c|c|c|c|c|c|c|c|c|c|}
\hline \multirow[b]{2}{*}{$\begin{array}{l}\text { OTU } \\
\text { Number }\end{array}$} & \multirow[b]{2}{*}{ Classification } & \multirow{2}{*}{$\begin{array}{c}\text { Total Relative } \\
\text { Abundance } \\
\text { (\%) }\end{array}$} & \multicolumn{3}{|c|}{ Treatment } & \multirow[b]{2}{*}{ SEM } & \multirow[b]{2}{*}{$P$-Value } & \multicolumn{2}{|c|}{ Contrasts } \\
\hline & & & CON & 12Bp & 24Bp & & & Linear & Quadratic \\
\hline OTU4 & (g) $5-7 \mathrm{~N} 15$ & 2.16 & & & & 0.30 & 0.07 & 0.03 & ns \\
\hline oTU6 & (g) $5-7 \mathrm{~N} 15$ & 1.30 & & & & 0.16 & 0.02 & 0.01 & ns \\
\hline OTU7 & (g) CF231 & 1.21 & & & & 0.33 & 0.01 & ns & 0.005 \\
\hline OTU12 & (f) Bacteroidaceae & 1.07 & & & & 0.35 & 0.002 & 0.001 & ns \\
\hline OTU13 & (g) Phascolarctobacterium & 1.04 & & & & 0.16 & 0.04 & 0.02 & ns \\
\hline OTU25 & (g) Prevotella & 0.56 & & & & 0.29 & $<0.001$ & 0.09 & $<0.001$ \\
\hline OTU29 & (f) Ruminococcaceae & 0.53 & & & & 0.36 & 0.002 & ns & 0.001 \\
\hline OTU37 & (f) Clostridiaceae & 0.47 & & & & 0.34 & 0.01 & 0.01 & ns \\
\hline OTU38 & (g) Treponema & 0.44 & & & & 0.13 & 0.10 & ns & 0.04 \\
\hline OTU39 & (g) Oscillospira & 0.41 & & & & 0.13 & 0.02 & 0.01 & ns \\
\hline OTU41 & (f) Lachnospiraceae & 0.38 & & & & 0.03 & 0.06 & 0.02 & ns \\
\hline OTU46 & (g) [Prevotella] & 0.36 & & & & 0.10 & 0.07 & ns & 0.04 \\
\hline OTU47 & (g) CF231 & 0.36 & & & & 0.18 & 0.02 & 0.01 & ns \\
\hline OTU50 & (f) Ruminococcaceae & 0.35 & & & & 0.10 & 0.01 & 0.003 & ns \\
\hline OTU56 & (f) Lachnospiraceae & 0.32 & & & & 0.07 & 0.03 & 0.02 & ns \\
\hline OTU58 & (f) Ruminococcaceae & 0.32 & & & & 0.09 & 0.02 & 0.01 & ns \\
\hline OTU59 & (s) Fibrobacter succinogenes & 0.32 & & & & 0.18 & 0.01 & 0.003 & ns \\
\hline OTU60 & (g) Paludibacter & 0.32 & & & & 0.09 & 0.09 & 0.03 & ns \\
\hline OTU66 & (g) $5-7 \mathrm{~N} 15$ & 0.30 & & & & 0.04 & 0.05 & 0.04 & ns \\
\hline OTU69 & (g) Bacteroides & 0.29 & & & & 0.09 & 0.01 & 0.01 & 0.04 \\
\hline OTU70 & (f) Ruminococcaceae & 0.29 & & & & 0.09 & 0.002 & 0.001 & 0.08 \\
\hline OTU73 & (f) Bacteroidaceae & 0.28 & & & & 0.10 & 0.01 & 0.002 & ns \\
\hline OTU83 & (o) Clostridiales & 0.25 & & & & 0.04 & 0.06 & 0.03 & ns \\
\hline OTU84 & (f) Clostridiaceae & 0.24 & & & & 0.04 & 0.05 & 0.03 & ns \\
\hline OTU86 & (f) Ruminococcaceae & 0.23 & & & & 0.05 & 0.02 & 0.01 & ns \\
\hline OTU92 & (f) Bacteroidaceae & 0.22 & & & & 0.09 & 0.01 & 0.002 & ns \\
\hline OTU93 & (g) $5-7 \mathrm{~N} 15$ & 0.21 & & & & 0.04 & 0.05 & 0.03 & ns \\
\hline OTU98 & (f) Ruminococcaceae & 0.20 & & & & 0.10 & 0.02 & 0.01 & ns \\
\hline OTU110 & (f) $\$ 24-7$ & 0.17 & & & & 0.06 & $<0.001$ & $<0.001$ & ns \\
\hline OTU117 & (f) Ruminococcaceae & 0.15 & & & & 0.05 & 0.003 & 0.001 & ns \\
\hline OTU123 & (f) Ruminococcaceae & 0.15 & & & & 0.04 & 0.07 & ns & 0.04 \\
\hline OTU129 & (f) Ruminococcaceae & 0.14 & & & & 0.03 & 0.02 & 0.01 & ns \\
\hline OTU132 & (o) Bacteroidales & 0.13 & & & & 0.04 & 0.001 & 0.001 & 0.03 \\
\hline OTU133 & (f) $\$ 24-7$ & 0.13 & & & & 0.04 & 0.03 & ns & 0.01 \\
\hline OTU134 & (g) Treponema & 0.13 & & & & 0.06 & 0.07 & 0.02 & ns \\
\hline OTU136 & (f) Ruminococcaceae & 0.13 & & & & 0.03 & 0.10 & 0.05 & ns \\
\hline OTU146 & (f) Ruminococcaceae & 0.12 & & & & 0.05 & 0.03 & 0.08 & 0.03 \\
\hline OTU147 & (g) Bacteroides & 0.12 & & & & 0.03 & 0.02 & 0.01 & ns \\
\hline OTU156 & (o) Bacteroidales & 0.12 & & & & 0.01 & 0.07 & ns & 0.05 \\
\hline OTU159 & (f) RF16 & 0.11 & & & & 0.02 & 0.05 & 0.02 & ns \\
\hline OTU165 & (o) Clostridiales & 0.11 & & & & 0.08 & 0.07 & 0.03 & ns \\
\hline OTU170 & (f) Ruminococcaceae & 0.10 & & & & 0.03 & 0.003 & 0.003 & 0.05 \\
\hline OTU172 & (f) Lachnospiraceae & 0.10 & & & & 0.05 & 0.01 & 0.004 & ns \\
\hline OTU176 & (f) [Barnesiellaceae] & 0.10 & & & & 0.03 & 0.02 & 0.01 & ns \\
\hline OTU178 & (f) Ruminococcaceae & 0.10 & & & & 0.02 & 0.09 & 0.03 & ns \\
\hline OTU179 & (f) Clostridiaceae & 0.10 & & & & 0.07 & 0.01 & 0.004 & ns \\
\hline OTU181 & (f) Rikenellaceae & 0.09 & & & & 0.02 & 0.07 & 0.03 & ns \\
\hline OTU195 & (f) Ruminococcaceae & 0.09 & & & & 0.02 & 0.01 & 0.004 & ns \\
\hline
\end{tabular}

\begin{tabular}{|c|c|}
\hline \multicolumn{2}{|c|}{ Abundance (\%) } \\
\hline $2-4$ & \\
\hline $1.5-2$ & \\
\hline $1.0-1.5$ & \\
\hline $0.5-1.0$ & \\
\hline $0.25-0.5$ & \\
\hline $0.01-0.25$ & \\
\hline $0.00-0.01$ & \\
\hline
\end{tabular}

Figure 2. Heatmap of relative abundance (\%) of operational taxonomic units (OTU) in the feces of cattle with a dietary effect of graded levels of molassed sugar beet pulp. Classification of OTU based on the SILVA database (https://www.arb-silva.de, version 123) with 97\% similarity at the order (o), family (f), genus (g), or species (s) level. Beet pulp inclusion rate: control diet $(\mathrm{CON})=0 \mathrm{~g} / \mathrm{kg}, 12 \mathrm{Bp}=120 \mathrm{~g} / \mathrm{kg}, 24 \mathrm{Bp}$ $=240 \mathrm{~g} / \mathrm{kg} . \mathrm{ns}=$ nonsignificant $P$-value of contrast. 


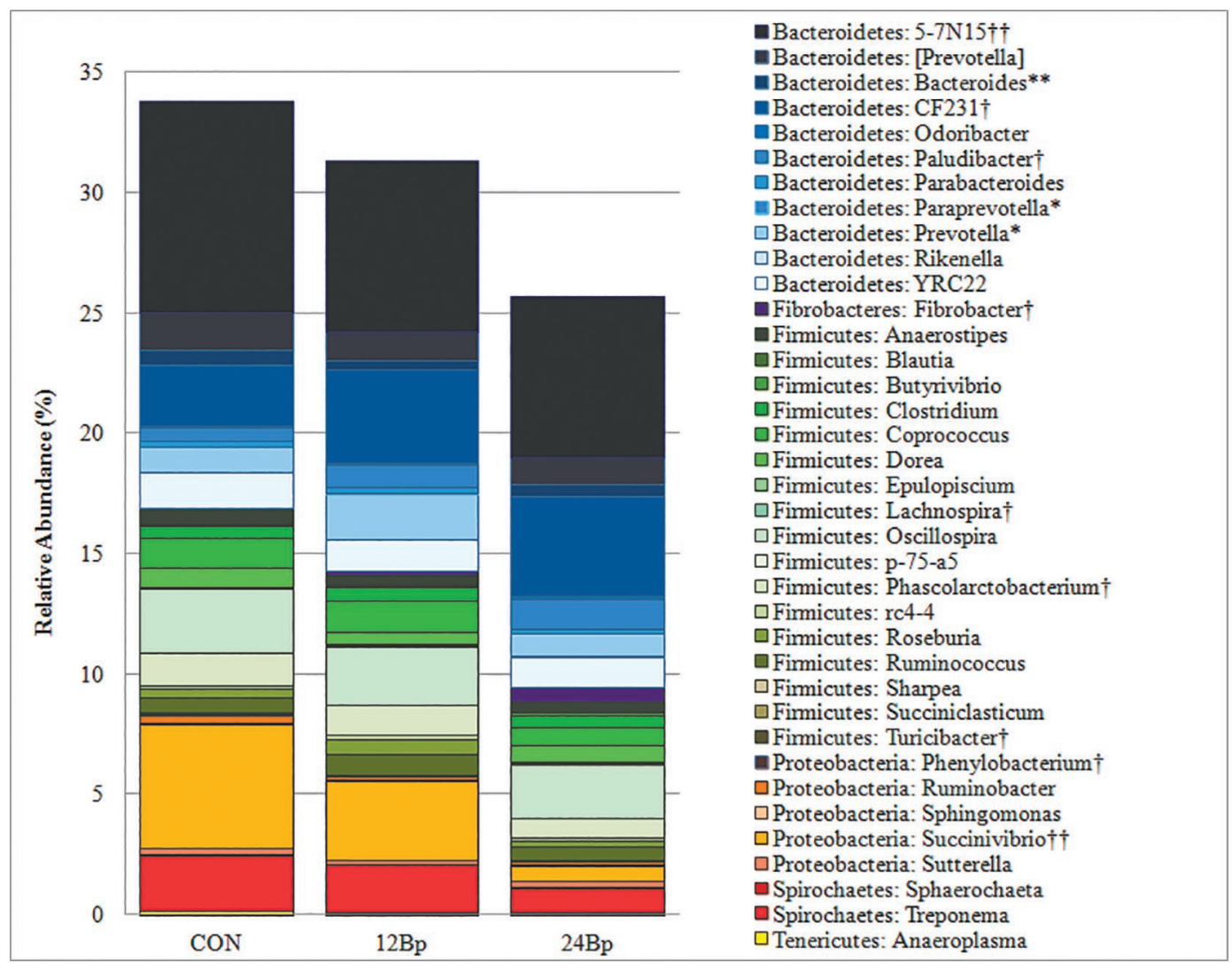

Figure 3. Relative abundance of genera identified from operational taxonomic units (OTU) representing more than $0.1 \%$ of the total abundance of sequences. †Linear contrast with $P \leq 0.05$. ††Linear contrast with $0.05 \leq P \leq 0.10$. ${ }^{*}$ Quadratic contrast with $P \leq 0.05$. $* *$ Quadratic contrast with $0.05 \leq P \leq 0.10$. Analysis by nonparametric multivariate ANOVA (ADONIS) showed no beet pulp $(\mathrm{Bp})$ effect $\left(\mathrm{R}^{2}=0.15 ; P=\right.$ 0.27 ), but analysis of similarity (ANOSIM) performed with Bray-Curtis revealed a trend toward significant differences between treatments $\left(\mathrm{R}^{2}\right.$ $=0.10 ; P=0.08$. Beta-dispersion analysis resulted in an insignificant overall effect of the Bp supplementation $(P=0.25)$ but a trend toward significance for the pairwise comparisons between control $(\mathrm{CON})$ and Bp inclusion rate of $240 \mathrm{~g} / \mathrm{kg}(24 \mathrm{Bp} ; P=0.08)$. $12 \mathrm{Bp}=120 \mathrm{~g} / \mathrm{kg}$ beet pulp inclusion rate.

\section{Effects on Fecal pH, Short-Chain Fatty Acids, and Bacterial Populations}

Too much starch escaping microbial degradation in the rumen and enzymatic hydrolysis in the small intestine will be subject to fermentation in the colon and cecum (Mills et al., 1999), inducing hindgut acidosis (Bissell and Hall, 2010; Gressley et al., 2011). Starch from corn grain is known to largely escape ruminal degradation, resulting in enzymatic degradation in the small intestine and fermentation in the hindgut (Mills et al., 1999), causing a decrease in fecal pH (Russell et al., 1981; Bissell and Hall, 2010). In contrast, dietary pectin and oligofructose from $\mathrm{Bp}$ are believed to be completely degraded by ruminal bacteria and therefore do not reach the hindgut of ruminants (Gressley et al., 2011). Even when pectin was infused into the abomasum of dairy cows, the recovery in the feces was very low, indicating a pronounced hindgut fermentation with no effect on fecal pH (Gressley and Armentano,
2005). Although the amount of corn in the CON diet was not large enough to induce acidotic hindgut conditions (Gressley et al., 2011), the present study showed that the replacement of corn grain with Bp can slightly elevate fecal $\mathrm{pH}$, which is also supported by the numerically lower concentration of fecal SCFA. This would seem to indicate that the fermentation of $\mathrm{Bp}$ in the current experiment was largely complete in the rumen. However, changes in the fecal microbial population at the genus level would indicate that there was a change in the substrate that reached the hindgut in diets where Bp replaced corn grain. Specifically, increases in the relative abundance of Lachnospira in the feces of animals fed $24 \mathrm{Bp}$ may be indicative of increased pectin reaching the hindgut as pectin is the preferred substrate of fermentation for Lachnospira spp. (Ludwig et al., 2011). A similar increase in Paludibacter spp. found at the $24 \mathrm{Bp}$ inclusion also indicate an increase in glucose substrate in the hindgut, because glucose is the preferred substrate of Paludibacter spp. (Ludwig 
et al., 2010). Both pectin and glucose would have been increased in the $24 \mathrm{Bp}$ diet compared with the corn grain based on the standard composition of molassed beet pulp. However, the fecal content was not analyzed for glucose and pectin content. In support of this hypothesis is that the major fermentation product of both Lachnospira spp. and Paludibacter spp. is acetate, which was numerically increased in the feces with the highest inclusion of Bp. Further research is required to look at the bypass of nutrients from the rumen into the hindgut to determine the specific changes in substrate availability to the hindgut microbial population. In addition, it was previously found that feeding high amounts of starch can interfere with ruminal fiber degradation (Carey et al., 1993; van Vuuren et al., 2010), thus in cows fed the CON diet ruminal fiber degradation was presumably lower than in cows fed diets containing Bp. This might have led to a higher availability of undegraded dietary fiber in the hindgut, which increased the hindgut fermentation in the CON group. However, this is in opposition to our findings that fecal Fibrobacter spp. increased with increasing levels of Bp in the diet. Fibrobacter spp. preferentially ferment $\beta$-glucans and produce acetate as a product of fermentation (Spain et al., 2010). The most predominant member of the Fibrobacter genus in the rumen is Fibrobacter succinogenes, which is known for producing fibro-slime, pilin, endoglucanases, and type II and III secretion proteins in cellulose cultures (Burnet et al., 2015), and in the current study OTU59 was identified to $97 \%$ similarity as Fibrobacter succinogenes. However, as only $1.5 \%$ less starch was provided and only $0.5 \%$ more NDF in the 24Bp diet, the increase in Fibrobacter spp. in the $24 \mathrm{Bp}$ treatment is likely not a result of a changes in dietary substrate. Therefore, it may be that the abundance of Fibrobacter spp. increased in the $24 \mathrm{Bp}$ diet as a result of increased hindgut retention time, which allowed for the more extensive colonization of these microbes. Other studies have shown increased viscosity of digesta in other species fed Bp (El Abed et al., 2011) and although digesta viscosity was not measured in the present study, the retention time based on Bp addition to the diet may have had an effect on the present results and should be included in future studies.

Fibrobacter succinogenes is also known to synergistically work with other ruminal microbes (Fukuma et al., 2015). The significant increase in $F$. succinogenes in the $24 \mathrm{Bp}$ treatment combined with the increased diversity and species richness supports the idea of increased hindgut retention time in the $24 \mathrm{Bp}$ diet, allowing for colonization and fermentation of substrates. These results indicate a positive influence of molassed sugar beet pulp up to $24 \%$ replacing corn grain, as increases in diversity are considered ecologically beneficial and indicate a healthy microbiome (Lozupone et al., 2012).

Our finding of linearly decreased relative butyrate concentrations in the feces of cows fed increasing levels of Bp diets supports previous studies finding that microbial degradation of corn starch promotes butyrate production (van Vuuren et al., 2010; Liu et al., 2015; Münnich et al., 2018b). Numerical increases in the fecal $\mathrm{pH}$ are also congruent with the decreases in some known lactic acid producing bacteria such as Turicibacter and Succinivibrio spp. found with 24Bp inclusion. However, interpretation of the effects of these population changes is limited by database use for sequence identity, for example the most abundant genus is an unknown environmental microorganism and the most abundant OTU could not be identified beyond the family level. Furthermore, it is necessary to take into consideration that the sampling of feces was only performed once at the end of a 28-d feeding period, and therefore, there is a bias based on a single fecal replicate per cow for fecal pH, SCFA analysis, and the relative abundances of bacterial population. These measurements can vary within an animal over a 24-h period as well as over several days. However, the use of a single sampling time provides a reference point for understanding the changes effecting the hindgut once the gastrointestinal tract has stabilized to a change in dietary regimen.

\section{CONCLUSIONS}

We hypothesized that feeding diets with high proportions of Bp instead of corn grain would increase ruminal $\mathrm{pH}$ and reduce the amount of hindgut fermentation, likely explaining positive effects of $\mathrm{Bp}$ on improving fiber degradation. Despite the lack of significant effects of $\mathrm{Bp}$ supplementation on chewing activity, ruminal $\mathrm{pH}$, and fecal $\mathrm{pH}, \mathrm{Bp}$ feeding decreased the amplitude of $\mathrm{pH}$ variation and affected the fermentation profile and microbial community within the hindgut. These results warrant further investigation into the metabolic activity of the hindgut microbiome and the role of $\mathrm{Bp}$ on passage rate and hindgut health. The addition of $\mathrm{Bp}$ up to $24 \%$ inclusion replacing corn in lactating dairy cow diets decreased fecal butyrate but also increased the Fibrobacter population. This increase in fiber fermentation in the hindgut could have positive effects on host health without negatively affecting production.

\section{ACKNOWLEDGMENTS}

The authors thank the staff of the research station "Kremesberg" at the Vetmeduni Vienna (Austria) for their assistance throughout the animal trial. A. Dock- 
ner, M. Wild, S. Leiner, and S. Sharma (Institute of Animal Nutrition and Functional Plant Compounds, Vetmeduni Vienna) are highly appreciated for their support and expertise during the experiment. The authors also recognize the contribution of A. Sener (Institute of Animal Nutrition and Functional Plant Compounds) for her significant work in the laboratory. This project was funded by the "Sparkling Science" program of the Austrian Federal Ministry of Science, Research and Economy (BMWFW; Vienna, Austria). Funding for R. M. Petri was provided by the Vetmeduni Post-Doc Programme.

\section{REFERENCES}

Alamouti, A., A. M. Alikhani, G. R. Ghorbani, and Q. Zebeli. 2009. Effects of inclusion of neutral detergent soluble fiber sources in diets varying in forage particle size on feed intake, digestive processes, and performance of mid-lactation Holstein cows. Anim. Feed Sci. Technol. 154:9-23. https://doi.org/10.1016/j.anifeedsci 2009.07.002.

Allen, M. S. 1997. Relationship between fermentation acid production in the rumen and the requirement for physically effective fiber. J. Dairy Sci. 80:1447-1462. https://doi.org/10.3168/jds.S0022 -0302(97)76074-0.

Aschenbach, J. R., G. B. Penner, F. Stumpff, and G. Gäbel. 2011. Ruminant nutrition symposium: Role of fermentation acid absorption in the regulation of ruminal pH. J. Anim. Sci. 89:1092-1107. https: //doi.org/10.2527/jas.2010-3301.

Bhattacharya, A., and F. T. Sleiman. 1971. Beet pulp as a grain replacement for dairy cows and sheep. J. Dairy Sci. 54:89-94. https: //doi.org/10.3168/jds.s0022-0302(71)85783-1.

Bissell, H. A., and M. B. Hall. 2010. Cattle differ in ability to adapt to small intestinal digestion of starch. J. Dairy Sci. 93(E-Suppl. 1):845.

Burnet, M. C., A. C. Dohnalkova, A. P. Neumann, M. S. Lipton, R. D. Smith, G. Suen, and S. J. Callister. 2015. Evaluating models of cellulose degradation by Fibrobacter succinogenes S85. PLoS One 10:e0143809.

Caporaso, J. G., J. Kuczynski, J. Stombaugh, K. Bittinger, F. D. Bushman, E. K. Costello, N. Fierer, A. G. Peña, J. K. Goodrich, and J. I. Gordon. 2010. QIIME allows analysis of high-throughput community sequencing data. Nat. Methods 7:335-336. https://doi .org/10.1038/nmeth.f.303.

Carey, D. A., J. S. Caton, and M. Biondini. 1993. Influence of energy source on forage intake, digestibility, in situ forage degradation, and ruminal fermentation in beef steers fed medium-quality brome hay. J. Anim. Sci. 71:2260-2269. https://doi.org/10.2527/1993 $.7182260 \mathrm{x}$

Dann, H. M., M. Carter, K. Cotanch, C. Ballard, T. Takano, and R. Grant. 2007. Effect of partial replacement of forage neutral detergent fiber with by-product neutral detergent fiber in close-up diets on periparturient performance of dairy cows. J. Dairy Sci. 90:1789-1801. https://doi.org/10.3168/jds.2006-692.

Edgar, R. C. 2010. Search and clustering orders of magnitude faster than BLAST. Bioinformatics 26:2460-2461. https://doi.org/10 .1093/bioinformatics/btq461.

El Abed, N., R. Delgado, R. Abad, C. Romero, A. Fernández, M. J. Villamide Díaz, D. Menoyo Luque, J. Garcia Alonso, and R. M. Carabaño Luengo. 2011. Effect of sugar beet pulp fibre fractions on growth performance, fecal digestibility and digestive physiology in rabbits around weaning. Conference Paper: Giornate di Coniglicoltura, ASIC 2011. Forli, Italia.

Ertl, P., Q. Zebeli, W. Zollisch, and W. Knaus. 2015. Feeding of byproducts completely replaced cereals and pulses in dairy cows and enhanced edible feed conversion ratio. J. Dairy Sci. 98:1225-1233. https://doi.org/10.3168/jds.2014-8810.
Ertl, P., Q. Zebeli, W. Zollisch, and W. Knaus. 2016. Feeding of wheat bran and sugar beet pulp as sole supplements in high forage diets emphasizes the potential of dairy cattle for human food supply. J. Dairy Sci. 99:1228-1236. https://doi.org/10.3168/jds.2015-10285.

Fanchone, A., P. Nozière, J. Portelli, B. Duriot, V. Largeau, and M. Doreau. 2013. Effects of nitrogen underfeeding and energy source on nitrogen ruminal metabolism, digestion, and nitrogen partitioning in dairy cows. J. Anim. Sci. 91:895-906. https://doi.org/10 $.2527 /$ jas.2012-5296.

Fukuma, N. M., S. Koike, and Y. Kobayashi. 2015. Monitoring of gene expression in Fibrobacter succinogenes S85 under the co-culture with non-fibrolytic ruminal bacteria. Arch. Microbiol. 197:269 276. https://doi.org/10.1007/s00203-014-1049-0.

Gressley, T. F., and L. E. Armentano. 2005. Effect of abomasal pectin infusion on digestion and nitrogen balance in lactating dairy cows. J. Dairy Sci. 88:4028-4044. https://doi.org/10.3168/jds.S0022 $-0302(05) 73089-7$.

Gressley, T. F., M. B. Hall, and L. E. Armentano. 2011. Ruminant Nutrition Symposium: Productivity, digestion, and health responses to hindgut acidosis in ruminants. J. Anim. Sci. 89:1120-1130. https://doi.org/10.2527/jas.2010-3460.

Hall, M. B., W. H. Hoover, J. P. Jennings, and T. K. M. Webster. 1999. A method for partitioning neutral detergent-soluble carbohydrates. J. Sci. Food Agric. 79:2079-2086. https://doi.org/10.1002/ (sici)1097-0010(199912)79:15\%3C2079:aid-jsfa502\%3E3.3.co;2-q.

Huhtanen, P. 1988. The effects of supplementation of silage diet with barley, unmolassed sugar beet pulp and molasses on organic matter, nitrogen and fibre digestion in the rumen of cattle. Anim. Feed Sci. Technol. 20:259-278. https://doi.org/10.1016/0377 -8401(88)90001-6.

Humer, E., R. M. Petri, J. R. Aschenbach, B. J. Bradford, G. B. Penner, M. Tafaj, K.-H. Südekum, and Q. Zebeli. 2018. Invited review: Practical feeding management recommendations to mitigate the risk of subacute ruminal acidosis in dairy cattle. J. Dairy Sci. 101:872-888. https://doi.org/10.3168/jds.2017-13191.

Kleen, J. L., G. A. Hooijer, J. Rehage, and J. P. T. M. Noordhuizen. 2003. Subacute ruminal acidosis (SARA): A review. J. Vet. Med. A Physiol. Pathol. Clin. Med. 50:406-414. https://doi.org/10.1046/j .1439-0442.2003.00569.x.

Liu, J., Y. Y. Pu, Q. Xie, J. K. Wang, and J. X. Liu. 2015. Pectin induces an in vitro rumen microbial population shift attributed to the pectinolytic Treponema group. Curr. Microbiol. 70:67-74. https://doi.org/10.1007/s00284-014-0672-y.

Lozupone, C. A., J. I. Stombaugh, J. I. Gordon, J. K. Jansson, and R. Knight. 2012. Diversity, stability and resilience of the human gut microbiota. Nature 489:220-230. https://doi.org/10.1038/ nature11550.

Ludwig, W., J. Euzeby, and W. B. Willams. 2010. Genus IV Paludibacter. Page 76 in Bergey's Manual of Systematic Bacteriology. 2nd ed. Vol. 4: The Bacteroidetes, Spirochaetes, Tenericutes (Mollicutes), Acidobacteria, Fibrobacteres, Fusobacteria, Dictyoglomi, Gemmatimonadetes, Lentisphaerae, Verrucomicrobia, Chlamydiae, and Planctomycetes. P. Vos, G. Garrity, D. Jones, N. R. Krieg, W. Ludwig, F. A. Rainey, K. H. Schleifer, and W. B. Whitman, ed. Springer Science and Business Media, Berlin, Germany.

Ludwig, W., K. H. Schleifer, and W. B. Whitman. 2011. Family V Lachnospiraceae. Page 921 in Bergey's Manual of Systematic Bacteriology. 2nd ed. Vol. 3: The Firmicutes. P. Vos, G. Garrity, D. Jones, N. R. Krieg, W. Ludwig, F. A. Rainey, K. H. Schleifer, and W. B. Whitman, ed. Springer Science and Business Media, Berlin, Germany.

Mills, J. A. N., J. France, and J. Dijkstra. 1999. A review of starch digestion in the lactating dairy cow and proposals for a mechanistic model: 2. Postruminal starch digestion and small intestinal glucose absorption. J. Anim. Feed Sci. 8:291-340. https://doi.org/ $10.22358 /$ jafs $/ 69123 / 1999$

Münnich, M., R. Khiaosa-ard, F. Klevenhusen, A. Hilpold, A. KholParisini, and Q. Zebeli. 2017. A meta-analysis of feeding sugar beet pulp in dairy cows: Effects on feed intake, ruminal fermentation, performance, and net food production. Anim. Feed Sci. Technol. 224:78-89. https://doi.org/10.1016/j.anifeedsci.2016.12.015. 
Münnich, M., A. Khol-Parisini, F. Klevenhusen, B. U. Metzler-Zebeli, and Q. Zebeli. 2018b. Graded replacement of maize grain with molassed sugar beet pulp modulated ruminal microbial community and fermentation profile in vitro. J. Sci. Food Agric. 98:991-997. https://doi.org/10.1002/jsfa.8547.

Münnich, M., F. Klevenhusen, and Q. Zebeli. 2018a. Feeding of molassed sugar beet pulp instead of maize enhances net food production of high-producing dairy cows without impairing metabolic health. Anim. Feed Sci. Technol. 241:75-83. https://doi.org/10.1016/j .anifeedsci.2018.04.018.

Neubauer, V., E. Humer, I. Kröger, T. Braid, M. Wagner, and Q. Zebeli. 2018. Differences between $\mathrm{pH}$ of indwelling sensors and the $\mathrm{pH}$ of fluid and solid phase in the rumen of dairy cows fed varying concentrate levels. J. Anim. Physiol. Anim. Nutr. (Berl.) 102:343-349. https://doi.org/10.1111/jpn.12675.

Oltenacu, P. A., and B. Algers. 2005. Selection for increased production and the welfare of dairy cows: Are new breeding goals needed? Ambio 34:311-315. https://doi.org/10.1639/0044 $-7447(2005) 034[0311$ :sfipat]2.0.co;2.

Peterson, J., S. Garges, M. Giovanni, P. McInnes, L. Wang, J. A. Schloss, V. Bonazzi, J. E. McEwen, K. A. Wetterstrand, C. Deal, C. C. Baker, V. Di Francesco, T. K. Howcroft, R. W. Karp, R. D. Lunsford, C. R. Wellington, T. Belachew, M. Wright, C. Giblin, H. David, M. Mills, R. Salomon, C. Mullins, B. Akolkar, L. Begg, C. Davis, L. Grandison, M. Humble, J. Khalsa, A. R. Little, H. Peavy, C. Pontzer, M. Portnoy, M. H. Sayre, P. Starke-Reed, and S. Zakhari. J. Read, B. Watson, and M. Guyer. 2009. The NIH human microbiome project. Genome Res. 19:2317-2323. 10.1101/ gr.096651.109.

Plaizier, J. C., D. O. Krause, G. Gozho, and B. W. McBride. 2008. Subacute ruminal acidosis in dairy cows: The physiological causes, incidence and consequences. Vet. J. 176:21-31. https://doi.org/10 $.1016 / j . t v j 1.2007 .12 .016$.

Qumar, M., R. Khiaosa-ard, P. Pourazad, S. U. Wetzels, F. Klevenhusen, W. Kandler, J. R. Aschenbach, and Q. Zebeli. 2016. Evidence of in vivo absorption of lactate and modulation of short chain fatty acid absorption from the reticulorumen of non-lactating cattle fed high concentrate diets. PLoS One 11:e0164192. https://doi.org/10 .1371/journal.pone.0164192.

Russell, J. R., A. W. Young, and N. A. Jorgensen. 1981. Effect of dietary corn starch intake on ruminal, small intestinal and large intestinal starch digestion in cattle. J. Anim. Sci. 52:1170-1176. https://doi.org/10.2527/jas1981.5251170x.

Spain, A. M., C. W. Forsberg, and L. R. Krumholz. 2010. Genus I Fibrobacter. Pages 740-746 in Bergey's Manual of Systematic Bacteriology. 2nd ed. Vol. 4: The Bacteroidetes, Spirochaetes, Tenericutes (Mollicutes), Acidobacteria, Fibrobacteres, Fusobacteria, Dictyoglomi, Gemmatimonadetes, Lentisphaerae, Verrucomicrobia, Chlamydiae, and Planctomycetes. P. Vos, G. Garrity, D. Jones, N. R. Krieg, W. Ludwig, F. A. Rainey, K. H. Schleifer, and W.
B. Whitman, ed. Springer Science and Business Media, Berlin, Germany.

van Vuuren, A. M., V. A. Hindle, A. Klop, and J. W. Cone. 2010. Effect of maize starch concentration in the diet on starch and cell wall digestion in the dairy cow. J. Anim. Physiol. Anim. Nutr. (Berl.) 94:319-329. https://doi.org/10.1111/j.1439-0396.2008 .00911.x.

VDLUFA. 2012. Handbuch der Landwirtschaftlichen Versuchs-und Untersuchungsmethodik (VDLUFA-Methodenbuch), Bd. III Die chemische Untersuchung von Futtermitteln. VDLUFA-Verlag, Darmstadt, Germany.

Voelker, J. A., and M. Allen. 2003a. Polluted beet pulp substituted for high-moisture corn: 1. Effects on feed intake, chewing behavior, and milk production of lactating dairy cows. J. Dairy Sci. 86:35423552. https://doi.org/10.3168/jds.S0022-0302(03)73959-9.

Voelker, J. A., and M. Allen. 2003b. Pelleted beet pulp substituted for high-moisture corn: 3. Effects on ruminal fermentation, $\mathrm{pH}$, and microbial protein efficiency in lactating dairy cows. J. Dairy Sci 86:3562-3570. https://doi.org/10.3168/jds.S0022-0302(03)73961 -7 .

Vojvodić, A., D. Komes, I. Vovk, A. Belščak-Cvitanović, and A. Bušić. 2016. Compositional evaluation of selected agro-industrial wastes as valuable sources for the recovery of complex carbohydrates. Food Res. Int. 89:565-573. https://doi.org/10.1016/j.foodres.2016 .07 .023 .

Yang, W. Z., and K. A. Beauchemin. 2006. Physically effective fiber: Method of determination and effects on chewing, ruminal acidosis, and digestion by dairy cows. J. Dairy Sci. 89:2618-2633. https:// doi.org/10.3168/jds.S0022-0302(06)72339-6.

Zebeli, Q., J. Dijkstra, M. Tafaj, H. Steingass, B. Ametaj, and W. Drochner. 2008a. Modelling the adequacy of dietary fiber in dairy cows based on the responses of ruminal $\mathrm{pH}$ and milk fat production to composition of the diet. J. Dairy Sci. 91:2046-2066. https: //doi.org/10.3168/jds.2007-0572.

Zebeli, Q., and B. Metzler-Zebeli. 2012. Interplay between rumen digestive disorders and diet-induced inflammation in dairy cattle. Res. Vet. Sci. 93:1099-1108. https://doi.org/10.1016/j.rvsc.2012 .02 .004 .

Zebeli, Q., M. Tafaj, I. Weber, J. Dijkstra, H. Steingass, and W. Drochner. 2007. Effects of varying dietary forage particle size in two concentrate levels on chewing activity, ruminal mat characteristics, and passage in dairy cows. J. Dairy Sci. 90:1929-1942. https://doi .org/10.3168/jds.2006-354.

Zebeli, Q., M. Tafaj, I. Weber, H. Steingass, and W. Drochner. 2008b. Effects of dietary forage particle size and concentrate level on fermentation profile, in vitro degradation characteristics and concentration of liquid-or solid-associated bacterial mass in the rumen of dairy cows. Anim. Feed Sci. Technol. 140:307-325. https://doi .org/10.1016/j.anifeedsci.2007.04.002. 